\title{
Prediction of post-intervention fractional flow reserve in diffuse or sequential coronary stenosis considering the residual trans-stent pressure gradient
}

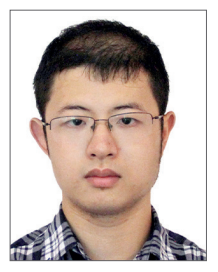

Xiaoyang Song ${ }^{1}$, MD; Naritatsu Saito ${ }^{1 *}$, MD; Yoshiaki Kawase ${ }^{2}, \mathrm{MD}$; Yusuke Yoshikawa ${ }^{1}$, MD; Erika Yamamoto, MD ${ }^{1}$; Munenori Okubo², MD; Hiroki Shiomi ${ }^{1}$, MD; Shin Watanabe ${ }^{1}$, MD;

Takeshi Kimura', MD; Hitoshi Matsuo², MD

1. Department of Cardiovascular Medicine, Kyoto University Graduate School of Medicine, Kyoto, Japan; 2. Department of Cardiovascular Medicine, Gifu Heart Center, Gifu, Japan

This paper also includes supplementary data published online at: www.asiaintervention.org

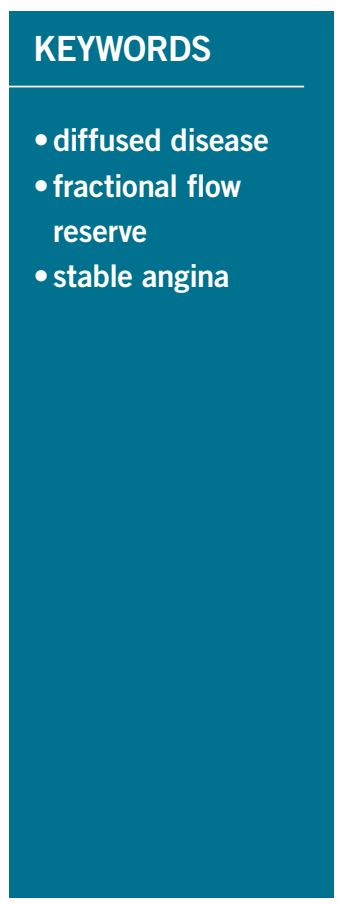

\begin{abstract}
Aims: Prediction of post-intervention fractional flow reserve (FFR) in a diffuse or sequential coronary lesion is difficult due to complex haemodynamic interactions between individual stenoses. Furthermore, the existence of a residual intra-stent pressure gradient makes the prediction difficult. We developed an equation predicting the post-intervention FFR in a diffuse/sequential lesion by considering intra-stent FFR gradient. The present study aims to validate the equation in an in vitro model and in clinical data.
\end{abstract}

Methods and results: In the in vitro experiment, three sequential coronary stenoses were made with a collateral flow. The correlation coefficient of the predicted FFR and the actual post-intervention FFR was 0.99 , and the absolute difference was $0.008 \pm 0.006(\mathrm{n}=50)$. In the clinical data analysis, the correlation coefficient was 0.41 , and the absolute difference was $0.06 \pm 0.05(n=67)$. We applied a fixed value of intra-stent FFR gradient and a collateral flow index so that the equation can be used in clinical practice. The correlation coefficient became 0.28 and the absolute difference became $0.06 \pm 0.06$.

Conclusions: In clinical practice, prediction of post-intervention FFR in a diffuse/sequential lesion is difficult even when residual intra-stent pressure gradient is considered.

\footnotetext{
*Corresponding author: Department of Cardiovascular Medicine, Kyoto University Graduate School of Medicine, 54 Shogoin-
} Kawahara-cho, Sakyo-ku, Kyoto,606-8507,Japan.E-mail: naritatu@kuhp.kyoto-u.ac.jp 


\section{Abbreviations}

CFI

dPR

collateral flow index

iFR instantaneous wave free ratio

IVUS intravascular ultrasound

LAD left anterior descending artery

LCX left circumflex artery

NSTEMI non-ST segment elevation myocardial infarction

OCT optical coherence tomography

PCI percutaneous coronary intervention

QCA quantitative coronary angiography

RCA right coronary artery

RFR resting full-cycle ratio

STEMI ST-segment elevation myocardial infarction

\section{Introduction}

Fractional flow reserve-guided percutaneous coronary intervention (PCI) is associated with a favourable outcome compared to angiography-guided $\mathrm{PCI}^{1,2}$. Fractional flow reserve (FFR) measurement is conducted under maximum hyperaemic conditions induced by intracoronary or intravenous administration of a vasodilator, which may cause side effects including vomiting, hypotension, and arrhythmia ${ }^{3,4}$. Recently, resting non-hyperaemic indices, including the instantaneous wave free ratio (iFR), have been developed to assess the functional severity of coronary steno$\mathrm{sis}^{5}$. iFR and other resting indices do not require the induction of hyperaemia, and thus hyperaemia-related complications are avoidable 3,4 . Another important advantage of iFR is that post-intervention iFR is predictable in a sequential or diffuse coronary lesion by the following simple equation ${ }^{6,7}: \mathrm{iFR}_{\text {post }}=\mathrm{iFR}_{\text {pre }}+\Delta \mathrm{iFR}$. Prediction of post-intervention FFR is usually considered difficult in FFR due to complex haemodynamic interactions between the individual stenoses under maximum hyperaemia ${ }^{8,9}$. Therefore, the current recommendation for a sequential or diffuse coronary lesions is to measure FFR distally, and perform a pressure pullback under maximum hyperaemia. Treatment of the most severely narrowed lesion is then determined by which of the lesions produces the largest $\triangle F F R^{10-12}$.

We consider that another factor that makes post-intervention FFR prediction in a diffuse/sequential lesion difficult is the existence of an intra-stent pressure gradient after intervention. The post-intervention intra-stent pressure gradient inevitably affects the post-intervention FFR ${ }^{13-16}$. We hypothesised that post-intervention FFR, in a diffuse/sequential coronary lesion, is predictable if the post-intervention intra-stent FFR is considered. Thus we developed a mathematical equation to predict post-intervention FFR in diffuse/sequential lesions by considering the intra-stent FFR gradient. The main purpose of the present study is to validate the equation in an in vitro circuit model and in clinical data.

\section{Methods}

\section{DERIVATION OF THE EQUATION}

De Bruyne et al described theoretic equations to predict the FFR of each stenosis in a tandem lesion ${ }^{8}$, but their application is limited to tandem lesions. We mathematically generalised the equations to be applicable to a diffuse/sequential coronary lesion in a previous study (Equation A) ${ }^{9}$.

$$
\begin{aligned}
\boldsymbol{F F R}_{\text {post }} & =\frac{\boldsymbol{P}_{d}-\boldsymbol{P}_{w}}{\boldsymbol{P}_{a}-\Delta P-\boldsymbol{P}_{w}}+\frac{\boldsymbol{P}_{w}\left(\boldsymbol{P}_{a}-\Delta P-\boldsymbol{P}_{d}\right)}{\boldsymbol{P}_{a}\left(\boldsymbol{P}_{a}-\Delta P-\boldsymbol{P}_{w}\right)} \\
& =\frac{F F R_{p r e}(1-C F I)-C F I \Delta F F R}{1-\Delta F F R-C F I}
\end{aligned}
$$

We wanted to formulate a novel equation in which post-intervention trans-stent FFR is considered. Consider a coronary circulation model simulating the diffuse/sequential coronary lesion with a collateral circulation (Figure 1). The abbreviations were

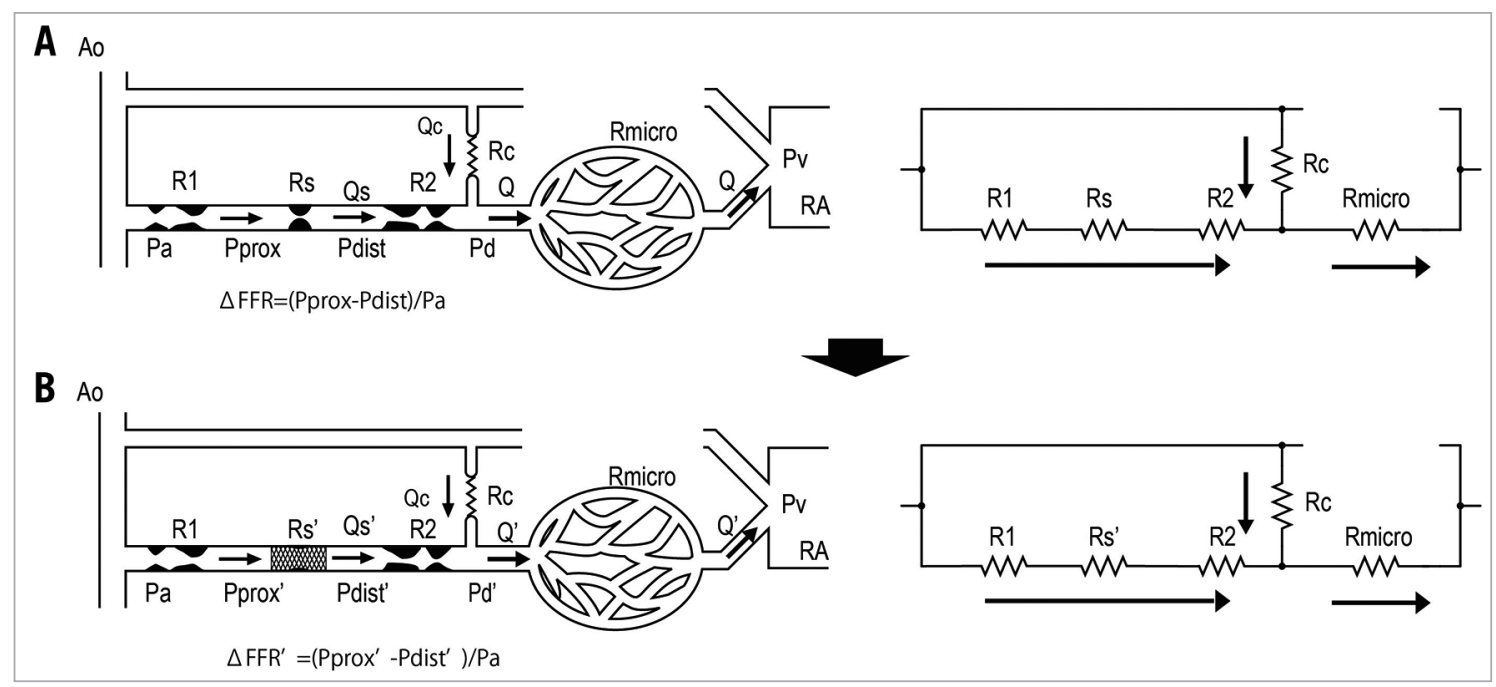

Figure 1. Schematic model representing the coronary circulation with a sequential lesion and a collateral circulation. (A) Before coronary intervention. The resistance of the target lesion is expressed as $R_{s}$. (B) After coronary intervention. The resistance of target lesion changes to $R_{s}^{\prime}$. 
defined as follows: $R_{s}$, resistance of the target coronary stenosis; $R_{1}$, summed resistance of the proximal stenoses; $R_{2}$, summed resistance of the distal stenoses; $\mathrm{R}_{\text {micro }}$, hyperaemic microcirculatory resistance; $R_{c}$, resistance of the collateral circulation; $P_{a}$, aortic pressure; $\mathrm{P}_{\text {prox }}$, pressure proximal to $\mathrm{R}_{\mathrm{s}} ; \mathrm{P}_{\text {dist }}$, pressure distal to $\mathrm{R}_{\mathrm{s}} ; \mathrm{P}_{\mathrm{d}}$, the most distal coronary pressure; $\mathrm{P}_{\mathrm{w}}$, coronary wedge pressure; and $\mathrm{P}_{\mathrm{v}}$, central venous pressure. The pre-intervention FFR was defined as FFR $_{\text {pre }}=\left(\mathrm{P}_{\mathrm{d}}-\mathrm{P}_{\mathrm{v}}\right) /\left(\mathrm{P}_{\mathrm{a}}-\mathrm{P}_{\mathrm{v}}\right) \fallingdotseq \mathrm{P}_{\mathrm{d}} / \mathrm{P}_{\mathrm{a}}$ because $\mathrm{P}_{\mathrm{v}}$ was usually considered to be zero while deriving the FFR indices. Pre-intervention FFR gradient across the target lesion was defined as $\triangle F F R=\left(\mathrm{P}_{\text {prox }}-\mathrm{P}_{\text {dist }}\right) / \mathrm{P}_{\mathrm{a}}$. The parameter calculated from $\left(\mathrm{P}_{\mathrm{w}}-\mathrm{P}_{\mathrm{v}}\right) /\left(\mathrm{P}_{\mathrm{a}}-\mathrm{P}_{\mathrm{v}}\right) \fallingdotseq \mathrm{P}_{\mathrm{w}} / \mathrm{P}_{\mathrm{a}}$ was originally named "fractional flow reserve of the collateral artery $\left(\mathrm{FFR}_{\text {coll }}\right)$ ". Later, the name "pressure derived collateral flow index (CFI)" was used for this parameter ${ }^{17}$. Because the collateral flow reserve of the collateral artery is usually called "pressure derived CFI" in other studies, we adopted this terminology to avoid confusion. All the postintervention parameters have been expressed by adding a prime to the pre-intervention parameters; thus, R's indicates the resistance of the target coronary lesion after PCI and $\mathrm{FFR}_{\text {post }}=\mathrm{P}_{\mathrm{d}}{ }_{\mathrm{d}} / \mathrm{P}_{\mathrm{a}}$ and $\triangle F F R^{\prime}=\left(\mathrm{P}_{\text {prox }}^{\prime}-\mathrm{P}_{\text {dist }}^{\prime}\right) / \mathrm{P}_{\mathrm{a}}$ are obtained. The pressure gradient across the stenosis was proportional to the flow because the flow was assumed to be the Hagen-Poiseuille flow in this model. Thus, the coronary circulation model can be considered analogous to an electric circuit. Figure 1 also describes the electric circuit that corresponds to the coronary circulation model. Under this assumption, the FFR indices can be expressed in terms of resistance as follows:

$$
\mathrm{CFI}=\frac{R_{\text {micro }}}{R_{c}+R_{\text {micro }}}
$$

$$
\begin{aligned}
F F R_{\text {pre }} & =\frac{R_{\text {micro }}}{\left(\frac{1}{\left.\frac{1}{R_{1}+R_{x}+R_{2}}+\frac{1}{R_{c}}\right)+R_{\text {micro }}}\right.} \\
\Delta \mathrm{FFR} & =\left(1-\mathrm{FFR}_{\text {pre }}\right) \frac{R_{x}}{R_{1}+R_{x}+R_{2}}
\end{aligned}
$$

$$
F F R_{\text {post }}=\frac{R_{\text {micro }}}{\left(\frac{1}{\frac{1}{R_{1}+R^{\prime}{ }_{x}+R_{2}}+\frac{1}{R_{c}}}\right)+R_{\text {micro }}}
$$

$$
\Delta \mathrm{FFR}^{\prime}=\left(1-\mathrm{FFR}_{\text {post }}\right) \frac{R_{x}^{\prime}}{R_{1}+R_{x}^{\prime}+R_{2}}
$$

By solving the above equations (1) to (5), the following Equation (B) is obtained:

$$
F F R_{\text {post }}=\frac{F F R_{\text {pre }}(1-C F I)-C F I \Delta F F R-\Delta F F R^{\prime}\left(F F R_{\text {pre }}-C F I\right)}{1-\Delta F F R-C F I}
$$

The detailed process of derivations of Equation $\mathrm{B}$ is given in Appendix 1.

\section{IN VITRO EXPERIMENT}

The experimental system was similar to that described in our previous studies (Figure 2). It consisted of a pump, systemic circulation, coronary circulation, and 5 constrictors placed in the coronary circulation. The pump produced a pulsatile flow at $60 \mathrm{rpm}$. The pressure and flow in the coronary artery could be adjusted by a valve placed in the aorta and constrictors placed in the coronary circulation. The coronary flow was approximately 300 to $500 \mathrm{~mL} / \mathrm{min}$. The circulating fluid was a $33 \%$ glycerine and $67 \%$ water a mixture comparable to the viscosity of blood. The systemic and coronary circulations were made of silicone rubber tubes that mimic the human arterial system. The inner diameter of the coronary artery was $4 \mathrm{~mm}$ and the inner diameter of the aorta was $12 \mathrm{~mm}$. The constrictors made variable stenoses in the coronary artery by a screw rotation movement. The constrictor names correspond to the names of the resistances in the schematic model in Figure 1. FFR measurements were conducted using three 0.014 inch pressure wires (Abbott Vascular, Santa Clara, CA, USA), one placed in the proximity of $\mathrm{R}_{\mathrm{s}}$, another placed distally to $R_{s}$, and one placed distally to $R_{2}$.

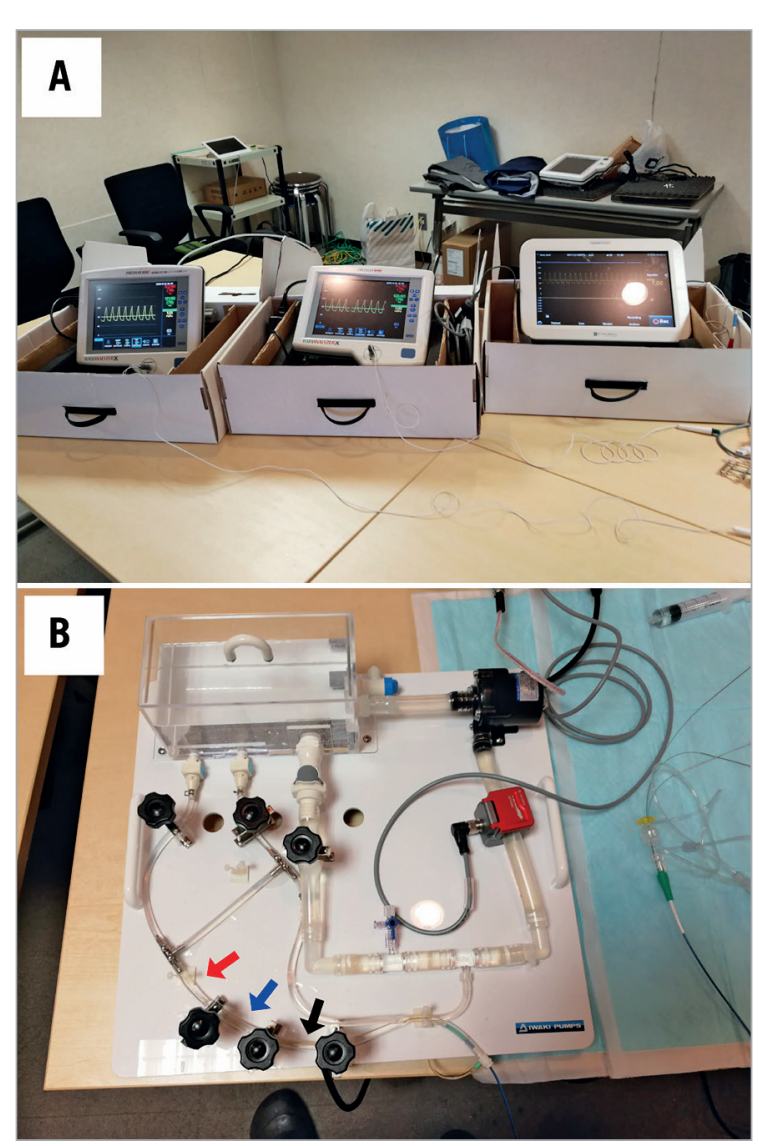

Figure 2. In vitro experimental system. (A) The simulation system comprising a pump as well as systemic and coronary circulation. (B) Three pressure wires are placed in the coronary circulation: one placed proximally to the target stenosis (black arrow), another placed distally to the target stenosis (blue arrow), and the last one placed in the most distal point of the coronary circulation (red arrow). 
The experiment was conducted in the following sequence. Variable degrees of coronary microcirculation and collateral circulation were randomly created by the constrictors. Variable degrees of three sequential coronary stenoses were randomly generated. Then, $\mathrm{P}_{\mathrm{a}}, \mathrm{P}_{\text {prox }}, \mathrm{P}_{\text {dist }}$, and $\mathrm{P}_{\mathrm{d}}$ were recorded by using three pressure wires, and $F_{F R}$ pre and $\triangle F F R$ were calculated. $P_{w}$ was obtained during a temporary occlusion of the distal part of the coronary artery, and pressure derived CFI was calculated. After partially releasing the stenosis of the target stenosis $\left(\mathrm{R}_{\mathrm{s}}\right), \mathrm{P}_{\text {prox }}, \mathrm{P}_{\text {dist }}$, and $\mathrm{P}_{\mathrm{d}}$, were recorded, and then $F_{\text {post }}$ and $\triangle F F R$ were calculated. The apparent FFR after partially releasing the target stenosis $\left(\mathrm{FFR}_{\text {apparent }}\right)$ was defined as $\mathrm{FFR}_{\text {apparent }}=\mathrm{FFR}_{\text {pre }}+\Delta \mathrm{FFR}$, and the predicted value of FFR ( FFR $_{\text {predicted }}$ ) was calculated using Equation A. The adjusted value of FFR considering the residual pressure gradient across the target stenosis $\left(\mathrm{FFR}_{\text {adjusted }}\right)$ was calculated using Equation B. $\mathrm{FFR}_{\text {apparent }}, \mathrm{FFR}_{\text {predicted }}$, and $\mathrm{FFR}_{\text {adjusted }}$ were compared with $\mathrm{FFR}_{\text {post }}$.

\section{CLINICAL DATA ANALYSIS}

Consecutive patients who underwent elective coronary intervention for diffuse/sequential coronary lesions in Gifu Heart Center between March 2017 and March 2018 were included in the study. The inclusion criteria required all physiological parameters including FFR $_{\text {pre }}, \Delta F F R, C F I, F_{\text {post }}$, and $\triangle F F R$ ' to be obtained. The data in this study consisted of 67 coronary diffuse/sequential lesions from 67 patients. As all data were retrospectively collected from the patients' records, the requirement of written informed consents was waived. The study protocol was developed in accordance with the Declaration of Helsinki and was approved by the institutional ethics committee.

Coronary angiography and pressure wire assessments of coronary stenoses were conducted using the conventional approach. Briefly, the patients were instructed not to consume caffeine for 12 hours before the procedure, and PCI was performed through the radial approach using a 6 or 7 Fr system. Intracoronary nitrates (300 ug) were administered to all patients before pressure wires (OptoWire ${ }^{\mathrm{TM}}$; Opsens Medical, Quebec, Canada) were introduced. Equalisation was performed 1 to $2 \mathrm{~mm}$ distal to the guiding catheter. The distal position of the pressure wire was documented by angiography. Angioplasty was performed using second-generation drug-eluting stents, which were all optimised using imaging devices such as intravascular ultrasound (IVUS) and optical coherence tomography (OCT). Maximum hyperaemia was induced by intravenous administration of adenosine. The pull-back recordings were conducted during maximum hyperaemia before and after PCI, and $\mathrm{FFR}_{\text {pre }}, \triangle \mathrm{FFR}, \mathrm{FFR}_{\text {post }}$, and $\triangle \mathrm{FFR}$ ' were obtained. Wedge pressure was recorded as the coronary pressure distal to the occluding balloon at 30 s after the balloon occlusion, and pressure derived CFI was also obtained for all patients. Like in the in vitro experiment, $\mathrm{FFR}_{\text {apparent }}, \mathrm{FFR}_{\text {predicted }}$, and $\mathrm{FFR}_{\text {adjusted }}$ were calculated from $\mathrm{FFR}_{\text {pre }}, \mathrm{CFI}, \triangle \mathrm{FFR}$, and $\triangle \mathrm{FFR}$ ', and compared with $\mathrm{FFR}_{\text {post. }}$. It is well-known that $\triangle F F R$ ' is obtained after PCI, and the coronary wedge pressure is not usually measured in real-world clinical practice. Equation B cannot be applied in clinical practice in this form. Thus, we calculated $\Delta \mathrm{FFR}^{\prime} / \mathrm{mm}^{\prime}$ defined as $\Delta \mathrm{FFR} \mathrm{F}^{\prime}$ by total stent length $(\mathrm{mm})$ and estimated $\Delta \mathrm{FFR}^{\prime}$ calculated as $\Delta \mathrm{FFR}^{\prime} / \mathrm{mm}$ multiplied by the implanted stent length $\left(\Delta F F{ }^{\prime}{ }_{\text {estimated }}\right)$. The estimated value of CFI ( CFI $\left._{\text {estimated }}\right)$ was obtained using the average value of CFI from this study. FFR $_{\text {fixed-adjusted }}$ was calculated by using $\triangle F F R^{\text {estimated }}$ and $\mathrm{CFI}_{\text {estimated }}$ in Equation B. FFR fixed-adjusted $_{\text {was com- }}$ pared with FFR ${ }_{\text {adjusted }}$

\section{STATISTICS}

$F_{\text {apparent }}, F_{\text {predicted }}$, and FFR adjusted $_{\text {were compared with FFR }}$ using linear regression analysis and the Bland-Altman plot in the in vitro experiment and the clinical data analysis. The absolute differences of FFR apparent FFR $_{\text {predicted }}$, and FFR ${ }_{\text {adjusted }}$ to FFR post $_{\text {were }}$ compared using a paired t-test for the in vitro experiment and in the clinical data analysis. The correlation coefficient and BlandAltman plot of $\mathrm{FFR}_{\text {fixed-adjusted }}$ to $\mathrm{FFR}_{\text {post }}$ were calculated, and the absolute difference of $\mathrm{FFR}_{\text {fixed-adjusted }}$ to $\mathrm{FFR}_{\text {post }}$ was compared with that of $\mathrm{FFR}_{\text {adjusted }}$ to $\mathrm{FFR}_{\text {post }}$ in the clinical data analysis. All continuous variables are presented as mean \pm standard deviation unless otherwise stated. A two-sided $\mathrm{p}$-value $<0.05$ was considered statistically significant in this study.

\section{Results \\ IN VITRO EXPERIMENT}

In the in vitro experiment, the procedures were repeated 50 times with changing degrees of each stenosis. Fifty different sets of pressure data were obtained in the in vitro experiment. FFR ${ }_{\mathrm{pre}}$, CFI, and $\triangle F F R$ were $0.60 \pm 0.08,0.29 \pm 0.08,0.17 \pm 0.06$, respectively. After partially releasing the target stenosis, $\triangle F F R '$ and $\mathrm{FFR}_{\text {post }}$ were $0.05 \pm 0.02$ and $0.67 \pm 0.08$. FFR $\mathrm{apparent}, \mathrm{FFR}_{\text {predicted }}$, and FFR $_{\text {adjusted }}$ were $0.78 \pm 0.08,0.71 \pm 0.10$, and $0.68 \pm 0.09$. The correlation coefficients of FFR apparent, $\mathrm{FFR}_{\text {predicted }}$, and FFR adjusted were 0.94, 0.99, and 0.99 (Figure 3). The absolute differences of FFR apparent' $\mathrm{FFR}_{\text {predicted }}$, and $\mathrm{FFR}_{\text {adjusted }}$ to $\mathrm{FFR}_{\text {post }}$ were $0.11 \pm 0.03,0.04 \pm 0.02$, and $0.008 \pm 0.006$, respectively ( $\mathrm{p}<0.001$, paired t-test). Equation $\mathrm{B}$ predicted the post-intervention FFR with a $1.3 \pm 1.0 \%$ error. The results indicated that Equation B perfectly predicted post-intervention FFR of diffuse/sequential coronary lesions when considering the residual FFR gradient in the in vitro experiment.

\section{CLINICAL DATA ANALYSIS}

Sixty-seven coronary diffuse/sequential lesions from 67 patients were analysed. Patients' demographics are summarised in Table 1. Briefly, the average age was $69.1 \pm 9.0$ years old, and 48 patients $(71.8 \%)$ were of male gender. Clinical presentations included 64 patients $(95.5 \%)$ with stable angina and 3 patients $(4.5 \%)$ with unstable angina. Non-ST segment elevation myocardial infarction (NSTEMI) and STEMI patients were not included in the study. Lesions and procedure characteristics are listed in Table 2. The locations of the lesions were 48 lesions $(71.6 \%)$ in the left anterior descending artery (LAD), 7 lesions (10.4\%) in the left circumflex artery (LCX), and 12 lesions (17.9\%) in the right coronary artery (RCA). All lesions were de novo coronary 

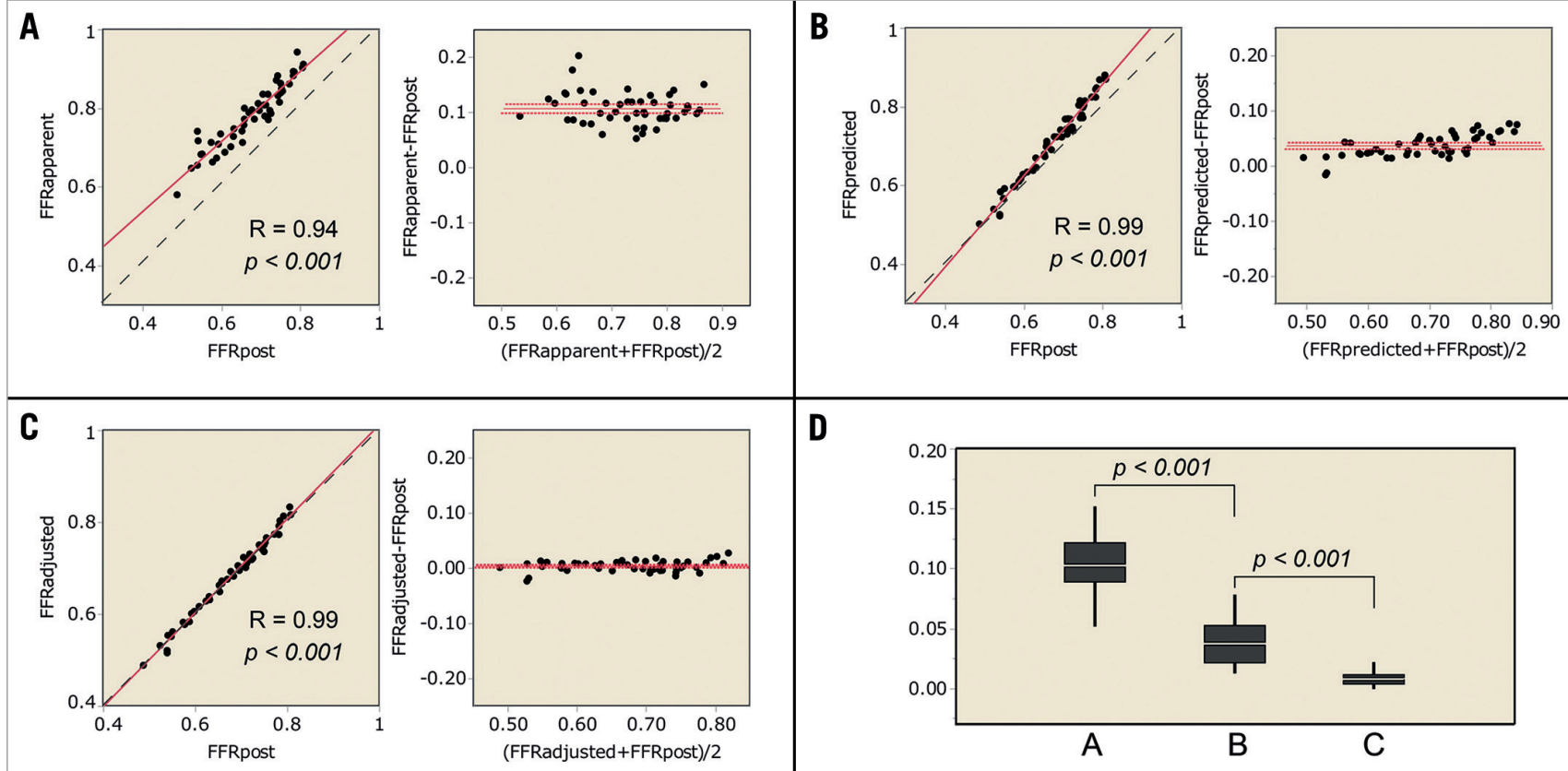

D

Figure 3. Results of the in vitro experiment. (A-C) Linear regression and Bland-Altman plots. The dotted line is the line of identity.

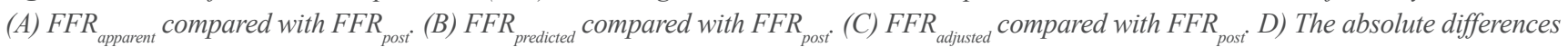

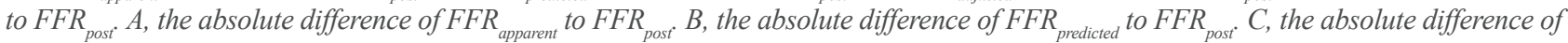
$F F R_{\text {adjusted }}$ to FFR post

Table 1. Baseline clinical characteristics of 67 patients.

\begin{tabular}{|l|c|}
\hline \multicolumn{1}{|c|}{ Variables } & Value \\
\hline Age (years) & $69.1 \pm 9.0$ \\
\hline Male gender, n (\%) & $48(71.6 \%)$ \\
\hline Height (cm) & $160.8 \pm 10.3$ \\
\hline Body weight (kg) & $66.2 \pm 15.1$ \\
\hline Diabetes mellitus, n (\%) & $34(51.5 \%)$ \\
\hline Hypertension, n (\%) & $46(70.0 \%)$ \\
\hline Dyslipidaemia, n (\%) & $40(61 \%)$ \\
\hline Smoker, n (\%) & $9(13.6 \%)$ \\
\hline Haemodialysis, n (\%) & $5(7.5 \%)$ \\
\hline Previous myocardial infarction, n (\%) & $13(19.4 \%)$ \\
\hline Left ventricular ejection fraction, \% & $62.5 \pm 10.7$ \\
\hline Stable angina, n (\%) & $64(95.5 \%)$ \\
\hline Unstable angina, n (\%) & $3(4.5 \%)$ \\
\hline
\end{tabular}

lesions. Stenosis diameter of the target lesion was $54.9 \pm 12.2 \%$, reference vessel diameter was $2.91 \pm 0.52 \mathrm{~mm}$, lesion length was $23.4 \pm 9.0 \mathrm{~mm}$, and the minimum lumen diameter was $1.30 \pm 0.35 \mathrm{~mm}$ obtained by quantitative coronary angiography (QCA). The preprocedural intravenous adenosine induced FFR $\left(\mathrm{FFR}_{\text {pre }}\right), \triangle \mathrm{FFR}$ of the target lesion, and CFI were $0.68 \pm 0.11$, $0.17 \pm 0.10$, and $0.23 \pm 0.11$, respectively. All target lesions were treated by implanting a second-generation drug-eluting stent without any complications. The procedure time was $92.9 \pm 31.1 \mathrm{~min}$ and the contrast volume was $99.9 \pm 40.6 \mathrm{~cm}^{3}$. The total number of implanted stents was $1.2 \pm 0.4$, and the total stent
Table 2. Procedural data in 67 sequential coronary lesions.

\begin{tabular}{|c|c|}
\hline Variable & Value \\
\hline \multicolumn{2}{|l|}{ Lesion location } \\
\hline LAD & $48(71.6 \%)$ \\
\hline LCX & $7(10.4 \%)$ \\
\hline $\mathrm{RCA}$ & $12(17.9 \%)$ \\
\hline \multicolumn{2}{|l|}{ Pre-FFR data } \\
\hline Pre-FFR & $0.68 \pm 0.11$ \\
\hline Collateral flow index $\left(=\mathrm{P}_{\mathrm{w}} / \mathrm{Pa}\right)$ & $0.17 \pm 0.10$ \\
\hline$\triangle F F R$ of the target lesion & $0.23 \pm 0.11$ \\
\hline \multicolumn{2}{|l|}{ Pre-QCA data } \\
\hline Lesion length, mm & $23.4 \pm 9.0$ \\
\hline Pre-reference diameter, $\mathrm{mm}$ & $2.91 \pm 0.52$ \\
\hline Pre-minimum lumen diameter, $\mathrm{mm}$ & $1.30 \pm 0.35$ \\
\hline Pre-\%DS, \% & $54.9 \pm 12.2$ \\
\hline \multicolumn{2}{|l|}{ Procedural data } \\
\hline Implanted stent number & $1.2 \pm 0.4$ \\
\hline Total stent length, mm & $29.9 \pm 13.0$ \\
\hline Procedure time, $\min$ & $92.9 \pm 31.1$ \\
\hline Contrast volume, cc & $99.9 \pm 40.6$ \\
\hline \multicolumn{2}{|l|}{ Post-FFR data } \\
\hline Post-FFR & $0.81 \pm 0.07$ \\
\hline Post- $\triangle$ FFR of the target lesion & $0.04 \pm 0.03$ \\
\hline$\Delta \mathrm{FFR} / \mathrm{mm}, \mathrm{mm}$ & $0.0015 \pm 0.0013$ \\
\hline \multicolumn{2}{|l|}{ Post-QCA data } \\
\hline Post-reference diameter, mm & $3.15 \pm 0.45$ \\
\hline Pre-minimum lumen diameter, $\mathrm{mm}$ & $3.00 \pm 0.45$ \\
\hline Post-\%DS, \% & $5.8 \pm 9.9$ \\
\hline
\end{tabular}



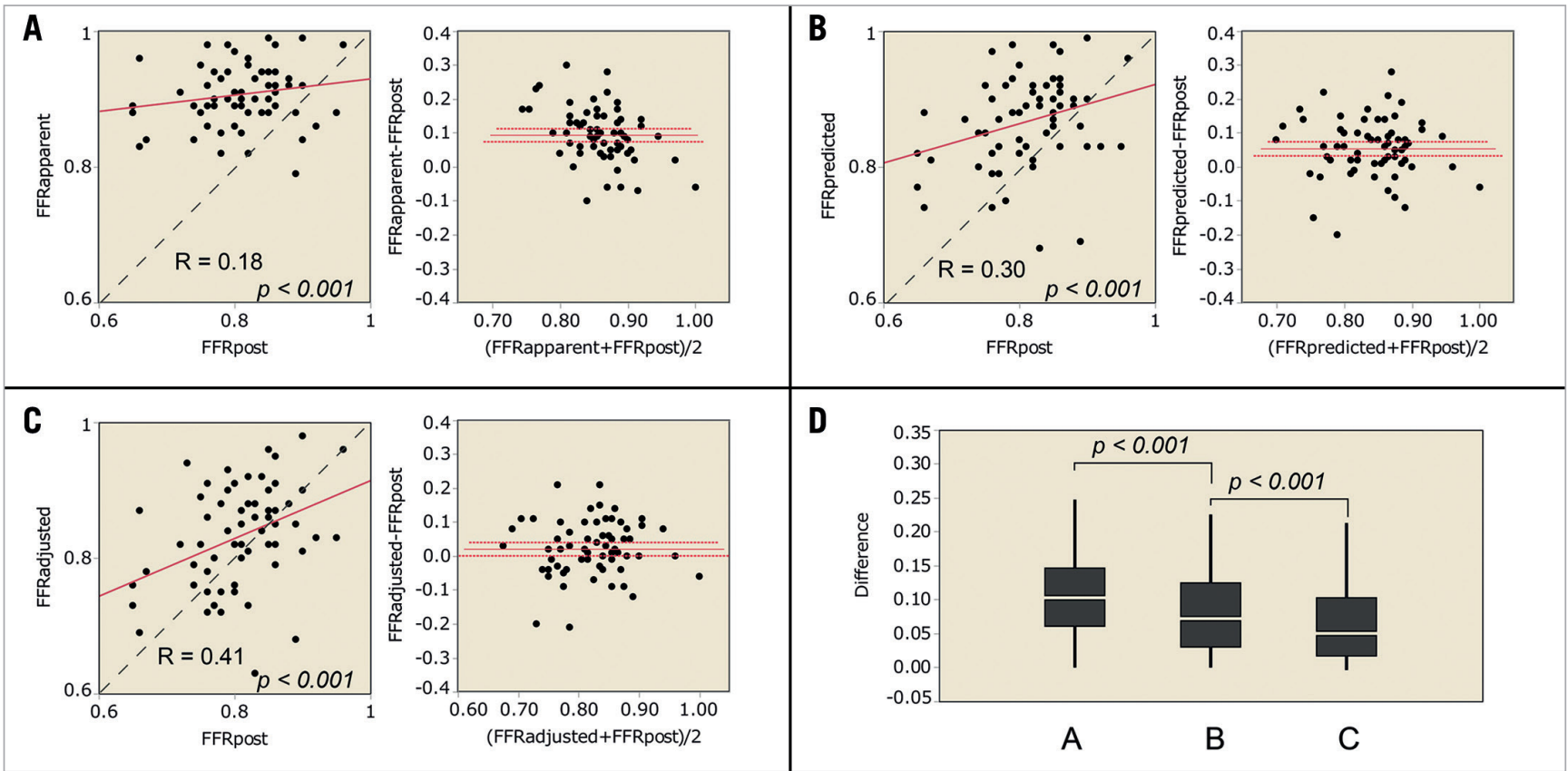

Figure 4. Results of the clinical data analyses. (A-C) Linear regression and Bland-Altman plots. The dotted line is the line of identity. (A)

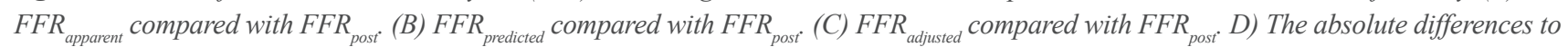

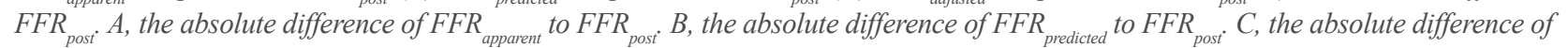
$F F R_{\text {adjusted }}$ to FFR ${ }_{\text {post }}$

length was $29.9 \pm 13.0 \mathrm{~mm}$. In post-procedural QCA, the reference diameter was $3.15 \pm 0.45 \mathrm{~mm}$, the minimum stent diameter was $3.00 \pm 0.45 \mathrm{~mm}$, and the diameter stenosis was $5.8 \pm 9.9 \%$. The postprocedural adenosine induced FFR $\left(\mathrm{FFR}_{\text {post }}\right)$ was $0.81 \pm 0.07$, $\triangle F F R$ of the stented lesion ( $\triangle F F R^{\prime}$ ) was $0.04 \pm 0.03, \Delta F F R ' /$

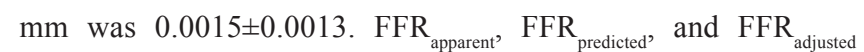
were calculated from the obtained data and were $0.91 \pm 0.05$, $0.87 \pm 0.07$, and $0.83 \pm 0.08$, respectively. The correlation coefficients of $\mathrm{FFR}_{\text {apparent }}, \mathrm{FFR}_{\text {predicted, }}$ and FFR $\mathrm{adjusted}_{\text {were }}$ 0.18, 0.30, and $0.41,(p<0.001$, Figure 4$)$. The absolute differences of $\mathrm{FFR}_{\text {apparent }}, \mathrm{FFR}_{\text {predicted }}$, and $\mathrm{FFR}_{\text {adjusted }}$ to $\mathrm{FFR}_{\text {post }}$ were $0.11 \pm 0.06$, $0.08 \pm 0.06$, and $0.06 \pm 0.05$, respectively ( $<<0.001$, paired t-test). Equation B was used to calculate the post-intervention FFR with an $8.0 \pm 7.0 \%$ error.
When the average value of CFI of 0.17 and $\triangle F_{F R} / \mathrm{mm}$ of 0.0015 were applied to Equation $\mathrm{B}, \mathrm{FFR}_{\text {fixed-adjusted }}$ was obtained. FFR $_{\text {fixed-adjusted }}$ was $0.83 \pm 0.07$, and the correlation coefficient of $\mathrm{FFR}_{\text {fixed-adjusted }}$ to $\mathrm{FFR}_{\text {post }}$ was $0.28(\mathrm{p}<0.001$, Figure 5). The absolute difference of $\mathrm{FFR}_{\text {fixed-adjusted }}$ to $\mathrm{FFR}_{\text {post }}$ was $0.06 \pm 0.06$, which was not significantly different from $\mathrm{FFR}_{\text {adjusted }}$ to $\mathrm{FFR}_{\text {post }}(\mathrm{p}=0.6420$, paired t-test). Equation B predicted the post-intervention FFR with an $8.0 \pm 7.2 \%$ error.

These results indicated that the accuracy of postprocedural FFR improved by taking the residual intra-stent FFR gradient into account, and the application of a fixed value of CFI and intrastent FFR gradient did not significantly lower the accuracy of the post-procedural FFR prediction. However, the prediction error of approximately $8 \%$ is considered too large for clinical practice use.
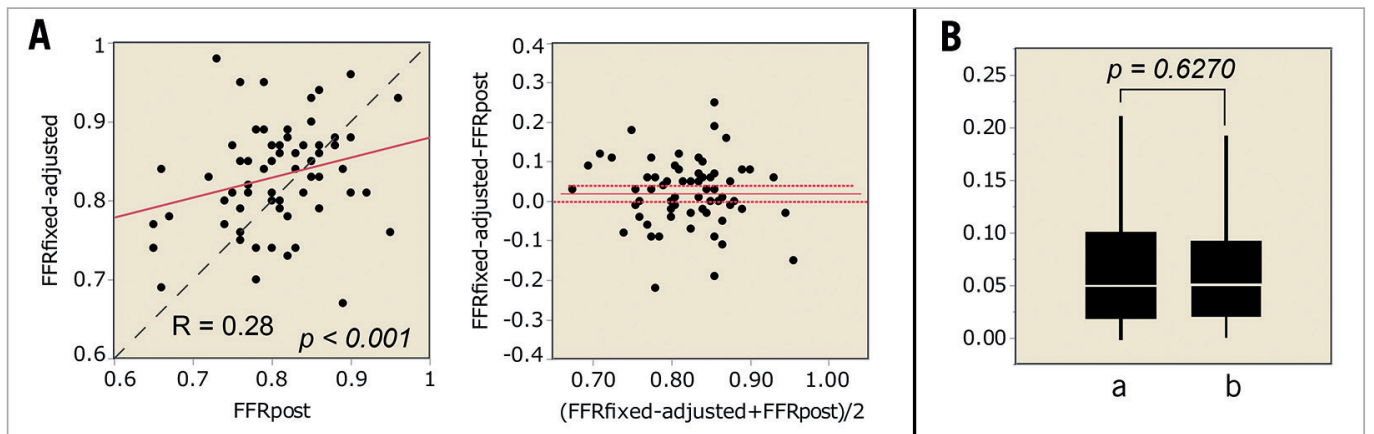

Figure 5. Estimated FFR value using fixed value of CFI and $\triangle F F R$ in clinical data analyses. A) Linear regression and Bland-Altman plots. B) The absolute differences. $a$ - the absolute difference of FFR adjusted ${ }^{\text {to } F F R_{\text {post }}{ } \text { - the absolute difference of FFR fixed-adjusted }}$ to FFR post 


\section{Discussion}

The main findings of the present study, which included the development of a novel equation which predicts the post-intervention FFR in diffuse/sequential coronary lesions, were that: the novel equation perfectly predicted post-intervention FFR of diffuse/ sequential coronary lesions in the in vitro model of coronary circulation; in the clinical data analysis, prediction accuracy of postintervention FFR in diffuse/sequential coronary lesions improved by taking the residual intra-stent FFR gradient into account and; the application of a fixed value of CFI and intra-stent FFR gradient did not significantly lower the accuracy of post-procedural FFR prediction. However, the prediction error in post-procedural FFR is considered too large to be used in clinical practice.

Previous studies have shown that PCI for stable angina is only beneficial in patients with significant myocardial ischaemia ${ }^{18,19}$. Although FFR has been regarded as the gold standard index for the invasive assessment of the physiological severity of coronary stenosis, the worldwide use of FFR remains low at around $5-10 \%$ of all PCIs ${ }^{20}$. The reasons for the low utilisation of FFR include the need for administration of hyperaemic agents, which is time consuming and may cause unpleasant complications ${ }^{3,4}$. Recently, resting indices including iFR have been developed to assess the functional severity of coronary stenosis. iFR is calculated by dividing the distal coronary pressure by the aortic pressure during the wave-free period under resting conditions. During the wave-free period, resistance in the cardiac cycle is considered to be minimal and constant. Following the results of two large randomised trials ${ }^{3,4}$, the current European guideline has updated iFR-guided revascularisation for stable angina to class $\mathrm{I}^{21}$. With the success of $\mathrm{iFR}$, other resting indices, including the resting full-cycle ratio (RFR) and the diastolic pressure ratio (dPR) have been introduced ${ }^{21,22}$. The main advantage of these resting indices over FFR is that they do not require the induction of hyperaemia, thus hyperaemia-related complications are avoidable. Another advantage is that post-intervention indices are predictable because resting coronary flow is maintained constant due to autoregulation of the coronary circulation. Kikuta et al described that iFR pullback predicted the physiological outcome of PCI with a high degree of accuracy ${ }^{6,7}$.

On the other hand, predicting post-intervention FFR is considered difficult in diffuse/sequential coronary stenoses because complicated haemodynamic interactions exist between individual coronary stenoses. De Bruyne et al described theoretical equations to predict the FFR of each stenosis in a tandem lesion ${ }^{8}$, but its application was limited to tandem lesions. Thus we developed an equation which can be used in a diffuse/sequential coronary lesion (Equation $\mathrm{A})^{9}$. However, the calculation requires coronary wedge pressure measurements, which makes the application of the equation in clinical practice difficult. Therefore, when using FFR to evaluate a sequential or diffuse coronary lesion, the pullback curve of the pressure wire under maximum hyperaemia is used to detect the target lesion with the largest $\triangle F F R$. After stenting the target lesion, a repeat measurement of pullback recordings of FFR is conducted ${ }^{10-12}$. The concept of this strategy was named "the rule of big delta" by Park et $\mathrm{al}^{11}$.

We consider that the existence of an intra-stent pressure gradient after intervention makes the prediction even more difficult ${ }^{13-16}$. In the present study, we developed an equation which predicts the post-intervention FFR in the diffuse/sequential coronary lesion by considering the residual intra-stent FFR gradient (Equation B). Equation B predicted the post-intervention FFR with a $1.3 \pm 1.0 \%$ error in the in vitro experiment. The study results indicate that the equation was almost perfect for predicting the post-intervention FFR in in vitro coronary circulation. However, the prediction error was $8.0 \pm 7.2 \%$ in the clinical data analysis, which was considered too large to be used in clinical practice. The results indicate that physicians need to conduct multiple pullback recordings of FFR in the treatment of a diffuse/sequential lesion based on "the rule of big delta".

Several reasons are proposed for the large prediction error which was observed in the clinical data analysis while the error was minimal in the in vitro study. First, keeping a steady state of maximal hyperaemia is mandatory during a pressure wire pullback for the assessment of diffuse/serial coronary lesions, while the FFR value is usually fluctuating during continuous infusion of intravenous adenosine ${ }^{23,24}$. Thus, the FFR pullback curve is inevitably affected by the fluctuation of maximal hyperaemia, which causes a considerable error in predicting the post-intervention FFR in a diffuse/ sequential coronary lesion. Second, the pressure wire was visually co-registered with angiography in this analysis. The operators were required to observe the pressure wire pullback curve and angiographic information at the same time and visually co-register the two pieces of information, which could represent the cause of prediction error. Third, Equation B includes 4 independent variables. All these variables are influenced by many factors in vivo, including the nervous system, the cardiovascular humoral factor, and stimuli during the procedure. Even small errors of each variable eventually become large errors in Equation B. In post-intervention iFR prediction, the equation includes only two variables, which is considered the great advantage of iFR.

\section{Limitations}

Several limitations exist in the present study. First, the in vitro coronary circulation model differed from the complex human coronary circulation in many ways. The model had no side branches between stenoses, and a single large collateral artery connected the donor and recipient arteries. Coronary arteries are not uniformly smooth like silicone tubes. These differences limit the direct applicability of an in vitro model to real world coronary physiology. Second, the clinical data analysis was retrospectively conducted; therefore the accuracy of data acquisition might be inferior to a prospective study. Third, the sample size of the present study was relatively small for both in vitro and clinical data sets. Fourth, coronary wedge pressure measurements were conducted during balloon dilatation without the continuous infusion of adenosine. Several studies reported that maximal hyperaemia can be induced 
by balloon occlusion of the coronary artery ${ }^{17,25}$, but the coronary occlusive hyperaemia might make a small difference that could affect the prediction of post-intervention FFR in diffuse/sequential coronary stenosis.

\section{Conclusions}

Prediction of post-intervention FFR in a diffuse/sequential lesion is only possible in an in vitro model of coronary circulation. In clinical practice, prediction is difficult due to considerable errors even when the residual intra-stent pressure gradient is considered. Physicians need to conduct multiple pullback recordings of FFR in the treatment of a diffuse/sequential lesion if they prefer to use FFR over resting indices.

\section{Impact on daily practice}

Prediction of post-intervention fractional flow reserve (FFR) in a diffuse/sequential lesion is only possible in an in vitro model. In clinical practice, prediction is difficult due to considerable errors even when residual intra-stent pressure gradient is considered. Physicians need to conduct multiple pullback recordings of FFR in the treatment of a diffuse/sequential lesion to obtain post-intervention FFR.

\section{Acknowledgements}

The authors would like to thank Ms. Sumiko Horie and Mr. Shiichi Hamaguchi for their advice regarding the in vitro experiments. Special thanks also goes to Editage (www.editage.jp) for English language editing.

\section{Conflict of interest statement}

The authors have no conflicts of interest to declare.

\section{References}

1. van Nunen LX, Zimmermann FM, Tonino P a L, Barbato E, Baumbach A, Engstrøm T, Klauss V, MacCarthy P a, Manoharan G, Oldroyd KG, Ver Lee PN, van't Veer M, Fearon WF, De Bruyne B, Pijls NHJ; FAME Study Investigators. Fractional flow reserve versus angiography for guidance of PCI in patients with multivessel coronary artery disease (FAME): 5-year follow-up of a randomised controlled trial. Lancet. 2015;6736:1853-60.

2. Tonino PA, De Bruyne B, Pijls NH, Siebert U, Ikeno F, van' t Veer M, Klauss V, Manoharan G, Engstrøm T, Oldroyd KG, Ver Lee PN, MacCarthy PA, Fearon WF; FAME Study Investigators. Fractional flow reserve versus angiography for guiding percutaneous coronary intervention. $N$ Engl J Med. 2009;360:213-24.

3. Götberg M, Christiansen EH, Gudmundsdottir IJ, Sandhall L, Danielewicz M, Jakobsen L, Olsson S-E, Öhagen P, Olsson H, Omerovic E, Calais F, Lindroos P, Maeng M, Tödt T, Venetsanos D, James SK, Kåregren A, Nilsson M, Carlsson J, Hauer D, Jensen J, Karlsson A-C, Panayi G, Erlinge D, Fröbert O; iFR-SWEDEHEART Investigators. Instantaneous Wave-free Ratio versus Fractional Flow Reserve to Guide PCI. N Engl J Med. 2017;376: 1813-23.
4. Davies JE, Sen S, Dehbi H-M, Al-Lamee R, Petraco R, Nijjer SS, Bhindi R, Lehman SJ, Walters D, Sapontis J, Janssens L, Vrints CJ, Khashaba A, Laine M, Van Belle E, Krackhardt F, Bojara W, Going O, Härle T, Indolfi C, Niccoli G, Ribichini F, Tanaka N, Yokoi H, Takashima H, Kikuta Y, Erglis A, Vinhas H, Canas Silva P, Baptista SB, Alghamdi A, Hellig F, Koo B-K, Nam C-W, Shin E-S, Doh J-H, Brugaletta S, Alegria-Barrero E, Meuwissen M, Piek JJ, van Royen N, Sezer M, Di Mario C, Gerber RT, Malik IS, Sharp ASP, Talwar S, Tang K, Samady H, Altman J, Seto AH, Singh J, Jeremias A, Matsuo H, Kharbanda RK, Patel MR, Serruys P, Escaned J. Use of the Instantaneous Wave-free Ratio or Fractional Flow Reserve in PCI. N Engl J Med. 2017;376:1824-34.

5. Sen S, Escaned J, Malik IS, Mikhail GW, Foale R a., Mila R, Tarkin J, Petraco R, Broyd C, Jabbour R, Sethi A, Baker CS, Bellamy M, Al-Bustami M, Hackett D, Khan M, Lefroy D, Parker KH, Hughes AD, Francis DP, Di Mario C, Mayet J, Davies JE. Development and validation of a new adenosine-independent index of stenosis severity from coronary waveintensity analysis: results of the ADVISE (ADenosine Vasodilator Independent Stenosis Evaluation) study. J Am Coll Cardiol. 2012; 59:1392-402.

6. Kikuta Y, Cook CM, Sharp ASP, Salinas P, Kawase Y, Shiono Y, Giavarini A, Nakayama M, De Rosa S, Sen S, Nijjer SS, Al-Lamee R, Petraco R, Malik IS, Mikhail GW, Kaprielian RR, Wijntjens GWM, Mori S, Hagikura A, Mates M, Mizuno A, Hellig F, Lee K, Janssens L, Horie K, Mohdnazri S, Herrera R, Krackhardt F, Yamawaki M, Davies J, Takebayashi H, Keeble T, Haruta S, Ribichini F, Indolfi C, Mayet J, Francis DP, Piek JJ, Di Mario C, Escaned J, Matsuo H, Davies JE. Pre-Angioplasty Instantaneous Wave-Free Ratio Pullback Predicts Hemodynamic Outcome In Humans With Coronary Artery Disease: Primary Results of the International Multicenter iFR GRADIENT Registry. JACC Cardiovasc Interv. 2018;11:757-67.

7. Nijjer SS, Sen S, Petraco R, Mayet J, Francis DP, Davies JER. The Instantaneous wave-Free Ratio (iFR) pullback: a novel innovation using baseline physiology to optimise coronary angioplasty in tandem lesions. Cardiovasc Revasc Med. 2015;16:167-71.

8. De Bruyne B, Pijls NHJ, Heyndrickx GR, Hodeige D, Kirkeeide R, Gould KL. Pressure-Derived Fractional Flow Reserve to Assess Serial Epicardial Stenoses : Theoretical Basis and Animal Validation. Circulation. 2000;101:1840-7.

9. Saito N, Matsuo H, Kawase Y, Watanabe S, Bao B, Yamamoto E, Watanabe H, Nakatsuma K, Ueno K, Kimura T. In vitro assessment of mathematically-derived fractional flow reserve in coronary lesions with more than two sequential stenoses. J Invasive Cardiol. 2013;25:642-9.

10. Kern MJ, Seto AH. Instantaneous Wave-Free Ratio Pressure Pullback With Virtual Percutaneous Coronary Intervention Planning: Seeing the Future of Coronary Interventions? JACC Cardiovasc Interv. 2018;11:768-70.

11. Park SJ, Ahn JM, Pijls NH, De Bruyne B, Shim EB, Kim YT, Kang SJ, Song H, Lee JY, Kim WJ, Park DW, Lee SW, Kim YH, Lee CW, Park SW. Validation of functional state of coronary 
tandem lesions using computational flow dynamics. Am J Cardiol. 2012;110:1578-84.

12. Matsuo H, Kawase Y. FFR and iFR guided percutaneous coronary intervention. Cardiovasc Interv Ther. 2016:31:183-95.

13. Tanaka N, Pijls NHJ, Yamashita J, Kimura Y, Ogawa M, Murata N, Sakoda K, Hoshino K, Hokama Y, Yamashina A. Analysis of suboptimal stent deployment using intravascular ultrasound and coronary pressure pullback measurement. $J$ Cardiol. 2017;69:613-8.

14. Van't Veer M, Pijls NHJ, Aarnoudse W, Koolen JJ, Van De Vosse FN. Evaluation of the haemodynamic characteristics of drugeluting stents at implantation and at follow-up. Eur Heart J. 2006; 27:1811-7.

15. Leesar MA, Satran A, Yalamanchili V, Helmy T, AbdulWaheed M, Wongpraparut N. The impact of fractional flow reserve measurement on clinical outcomes after transradial coronary stenting. EuroIntervention. 2011;7:917-23.

16. Matsuo A, Shimoo S, Takamatsu K, Tsuji Y, Kyodo A, Mera K, Koide M, Isodono K, Tsubakimoto Y, Sakatani T, Inoue K, Fujita H. Visualization of the improvement of myocardial perfusion after coronary intervention using motorized fractional flow reserve pullback curve. Cardiovasc Interv Ther. 2018;33:99-108.

17. Seiler C. The human coronary collateral circulation. Heart. 2003;89:1352-7.

18. Erne P, Schoenenberger AW, Burckhardt D, Zuber M, Kiowski W, Buser PT, Dubach P, Resink TJ, Pfisterer M. Effects of Percutaneous Coronary Interventions in Silent Ischemia. JAMA. 2007;297:1985-91.

19. Shaw LJ, Berman DS, Maron DJ, Mancini GBJ, Hayes SW, Hartigan PM, Weintraub WS, O'Rourke RA, Dada M, Spertus JA, Chaitman BR, Friedman J, Slomka P, Heller G V., Germano G, Gosselin G, Berger P, Kostuk WJ, Schwartz RG, Knudtson M, Veledar E, Bates ER, McCallister B, Teo KK, Boden WE; COURAGE Investigators Optimal medical therapy with or without percutaneous coronary intervention to reduce ischemic burden: results from the Clinical Outcomes Utilizing Revascularization and Aggressive Drug Evaluation (COURAGE) trial nuclear substudy. Circulation. 2008;117:1283-91.
20. Lee JM, Choi KH, Park J, Hwang D, Rhee T, Kim J, Park J, Kim HY, Jung HW, Song Y Bin, Hahn J, Hospital NN, Korea S, Korea S, Hospital U, Korea S, Korea S. Physiologic and Clinical Assessment of Resting Physiologic Indixes. Circulation. 2019; 139:889-900.

21. Neumann FJ, Sousa-Uva M, Ahlsson A, Alfonso F, Banning AP, Benedetto U, Byrne RA, Collet JP, Falk V, Head SJ, Jüni P, Kastrati A, Koller A, Kristensen SD, Niebauer J, Richter DJ, Seferovic PM, Sibbing D, Stefanini GG, Windecker S, Yadav R, Zembala MO; ESC Scientific Document Group. 2018 ESC/EACTS Guidelines on myocardial revascularization. Eur Heart J. 2019;40:87-165. Erratum in: Eur Heart J. 2019;40:3096.

22. Dattilo PB, Prasad A, Honeycutt E, Wang TY, Messenger JC. Contemporary patterns of fractional flow reserve and intravascular ultrasound use among patients undergoing percutaneous coronary intervention in the United States: Insights from the National Cardiovascular Data Registry. J Am Coll Cardiol. 2012;60:2337-9. 23. Toth GG, Johnson NP, Jeremias A, Pellicano M, Vranckx P, Fearon WF, Barbato E, Kern MJ, Pijls NHJ, De Bruyne B. Standardization of Fractional Flow Reserve Measurements. J Am Coll Cardiol. 2016;68:742-53.

24. Matsumura M, Johnson NP, Fearon WF, Mintz GS, Stone GW, Oldroyd KG, De Bruyne B, Pijls NHJ, Maehara A, Jeremias A. Accuracy of Fractional Flow Reserve Measurements in Clinical Practice: Observations From a Core Laboratory Analysis. JACC Cardiovasc Interv. 2017;10:1392-401.

25. Kawase Y, Omori H, Kawasaki M, Tanigaki T, Hirata T, Okamoto S, Ota H, Kikuchi J, Okubo M, Kamiya H, Hirakawa A, Suzuki T, Matsuo H. Postocclusional Hyperemia for Fractional Flow Reserve after Percutaneous Coronary Intervention. Circ Cardiovasc Interv. 2017;10:e05674.

\section{Supplementary data}

Supplementary Appendix 1. Derivation of equations A and B.

The supplementary data are published online at: www.asiaintervention.org 


\section{Supplementary data}

\section{Supplementary Appendix 1. Derivation of equations A and B.}

In this appendix, the derivations of equations $(A)$ and $(B)$ are presented. Consider a coronary circulation model that has sequential coronary stenosis (Figure 1 in the main text). All of the terminology is the same as that in the main text. When $P_{v}$ is considered 0 , the following equations are obtained: $F F R_{\text {pre }}=P_{d} / P_{a}, F F R_{\text {post }}=P^{\prime}{ }_{d} / P_{a}, C F I=P_{w} / P_{a}, \triangle F F R=$ $\left(\mathrm{P}_{\text {prox }}-\mathrm{P}_{\text {dist }}\right) / \mathrm{P}_{\mathrm{a}}$, and $\triangle F F R^{\prime}=\left(\mathrm{P}_{\text {prox }}^{\prime}-\mathrm{P}_{\text {dist }}\right) / \mathrm{P}_{\text {a }}$. All calculations are made under the assumption that the pressure drop across a stenosis is proportional to the flow. Under this assumption, the electric circuit can be considered an analogue of the fluid circulation and the pressure ratio can be expressed in terms of resistance. Note that the inverse of the equivalent resistance of two or more resistors connected in parallel is the algebraic sum of the inverses of the individual resistances. The following equations are obtained:

$$
\begin{gathered}
\mathrm{CFI}=\frac{R_{\text {micro }}}{R_{c}+R_{\text {micro }}} \\
\text { FFR } R_{\text {pre }}=\frac{R_{\text {micro }}}{\left(\frac{1}{\left.\frac{1}{R_{1}+R_{x}+R_{2}}+\frac{1}{R_{c}}\right)+R_{\text {micro }}}\right.} \\
\text { FFFR }_{\text {post }}=\frac{\left(1-\mathrm{FFR}_{\text {pre }}\right) \frac{R_{x}}{R_{1}+R_{x}+R_{2}}}{\left(\frac{R_{\text {micro }}}{\left.\frac{1}{R_{1}+R^{\prime}{ }_{x}+R_{2}}+\frac{1}{R_{c}}\right)+R_{\text {micro }}}\right.} \\
\Delta \mathrm{FFR}^{\prime}=\left(1-\mathrm{FFR}_{\text {post }}\right) \frac{R_{x}^{\prime}{ }_{x}+R_{x}^{\prime}+R_{2}}{R_{1}}
\end{gathered}
$$

By solving the above equations (1) to (4), $R_{\text {micro, }} R_{c}, R_{x}$ and $R_{x}^{\prime}$ are presented using CFI, $F F R_{\text {pre }}, \triangle F F R, \triangle F F R^{\prime}, R_{1}$ and $R_{2}$ : 


$$
\begin{gathered}
R_{\text {micro }}=\frac{\left(R_{1}+R_{2}\right)\left(F F R_{\text {pre }}-C F I\right)}{(1-C F I)\left(1-\left(F F R_{\text {pre }}+\Delta F F R\right)\right)} \\
R_{x}=\frac{\left(R_{1}+R_{2}\right) \Delta F F R}{\left(1-\left(F F R_{\text {pre }}+\Delta F F R\right)\right)} \\
R_{c}=\frac{\left(R_{1}+R_{2}\right)\left(F F R_{\text {pre }}-C F I\right)}{C F I\left(1-\left(F F R_{\text {pre }}+\Delta F F R\right)\right)} \\
R^{\prime}{ }_{x}=\frac{\left(R_{1}+R_{2}\right) \Delta F F R^{\prime}}{\left(1-\left(F F R_{\text {post }}+\Delta F F R^{\prime}\right)\right)}
\end{gathered}
$$

By substituting equations (6) to (9) into equation (5), the following equation (B) is obtained:

$$
F F R_{\text {post }}=\frac{F F R_{\text {pre }}(1-C F I)-C F I \Delta F F R-\Delta F F R^{\prime}\left(F F R_{\text {pre }}-C F I\right)}{1-\Delta F F R-C F I}
$$

Equation B calculates the post-intervention FFR with residual pressure gradient across the stent. When there is no residual pressure gradients across the stent, $\triangle F F R$ ' equals to 0 , then the following equation $(A)$ is obtained:

$$
F F R_{\text {post }}=\frac{F F R_{\text {pre }}(1-C F I)-C F I \Delta F F R}{1-\Delta F F R-C F I}
$$

Equation A calculates the post-intervention FFR when no residual intra-stent pressure gradients are existed. 